Sten Langmann and David Pick

Note: Reference omitted from this version:

Mignault, A., \& Chaudhuri, A. (2003). The many faces of a neutral face: Head tilt and perception of dominance and emotion. Journal of Nonverbal Behavior, 27, 111-132. 


\section{Dignity and ethics in research photography}

The aim of this paper is to provide new conceptual and practical insights about the issues associated with ethics and dignity when undertaking research involving the collection of photographic data. Case studies of photographs taken as part of a research project in Chennai, India are employed to illuminate the significance of dignity. The case studies reveal that dignity-in-context provides a useful conceptual tool that encapsulates the range of ethical issues that might be encountered. This concept has two dimensions. The first, dignity-in-outcome, assists deciding what and whether to photograph by drawing attention to the need for those being researched to benefit from the research, to present an authentic view of the situation, and to ensure that participants are not demeaned or reduced. The second is dignity-in-process that helps researchers decide why and how to photograph in terms of involving those being researched in the way an image is captured, choosing the right angle for the image, and the impression the image will give if and when it is published.

Keywords: Dignity, photography, research ethics

\section{Introduction}

The application of research photography has its origins in the field of social anthropology but increasing interest in using visual-based research methods has led to its wide application in social research (Banks, 2001; Close, 2007; Pink, 2006; Prosser \& Loxley, 2007). In spite of its usefulness and value, there is a need for deeper understanding of research ethics when collecting photographic data. While consideration of research ethics draws attention to informed consent and confidentiality, in the context of photography other complex issues become evident such as accuracy of the image, empowerment, how the identity of participants is affected, and how photographic research data are used and published (Banks, 2001; Boxall \& Ralph, 2009; Clark, Prosser \&Wiles, 2010; Wang \& Redwood-Jones, 2001; Young \& Barrett, 2000). These issues arise because of the particular nature of the relationship between the photographic researcher and those they are researching. Rather than recording a voice, 
observing behaviour or collecting survey data, the photographic researcher captures a person's image and with it intimate elements of their identity that other data collection methods cannot access. This places considerable ethical responsibilities on the researcher with respect to protecting those they are photographing. In this paper, it is argued that these issues can be encapsulated by the concept of dignity.

Dignity is commonly referred to in the photographic research literature (e.g., Rolph, Johnson \& Smith, 2009; Wiles, Coffey, Robison \& Heath, 2010) but its definition remains amorphous and its use uncertain. In this paper we first address this problem by defining and examining dignity in photographic research. We then develop this definition by introducing dignity-in-context, dignity-in-process, and dignity-in-outcome. How these concepts are applied in practice is illustrated through case examples drawn from a research project that focuses on poverty in Chennai, India. Poverty is often associated with resistance and struggle and the use of photography in this context raises issues of dignity that have general relevance. Through the analysis we generate conceptual and practical insights that other researchers can adopt to ensure the dignity of those they research is protected and enhanced.

\section{Dignity and Research Photography}

Photographic methods having been widely applied in social research (Stanczak, 2004) because they are a powerful means of documenting social relationships that exist between the people being researched and the places they inhabit (Joanou, 2009). Taking a photograph is a display interest in a particular situation and people but at the same time it is also an action that captures something of those being photographed they cannot effectively defend (i.e., their image). For example, when images of poverty are captured it becomes important for the researcher to have an 'understanding [of] the social relations inherent in the way such images 
are produced and read' (Smith \& Donnelly, 2004, p. 144). Otherwise there is the danger of the researcher capturing and presenting images that distort social situations or that can be interpreted in ways that compromise the dignity of those being researched.

Susan Sontag presented a pioneering exploration of ethical challenges in photography (Parsons, 2009). Sontag (1977, p. 10) describes a camera as an object that is predatory in nature, contending that taking a photograph can be an act of aggression because, 'to photograph people is to violate them, by seeing them as they never see themselves, by having knowledge of them they can never have; it turns people into objects that can be symbolically possessed'. Sontag's work provides a critique of the view that photographs are objective representations of the world (what she terms the 'thinking' aspect of photography). Sontag argues that photography is also a subjective process with a significant moral dimension in which feelings and emotions are important factors in that the camera is a tool that has potential to be lenient or cruel depending on the motives and techniques of the photographer. Solomon-Godeau (1994) characterises Sontag's ideas about thinking (objectivity) and feeling (subjectivity) as knowing objectively and knowing authentically. Parsons (2009, p. 290) contends that the research photographer listens 'to feelings, to gut reaction in the face of photographs'. Taking these arguments into account when collecting photographic research data, ethical considerations relating to the images being captured become of central importance, in particular, questions arise about how to protect and enhance the dignity of participants.

Although dignity of research participants has been considered in research (e.g., Steel, 2009), the concept itself has not been the subject of close attention and theorisation. Mehnert, Schroeder, Puhlmann, Muellerliele, \& Koch (2006) argue that an all-inclusive definition of 
dignity is difficult to compose. One approach is to define it as being something that is inherent to every individual, a Wesensmerkmal (Being), independent of a person's character attributes, intellectual capacity, occupation, traits, skills, etc., as well as their social status. Adopting this definition, the issue of dignity can be seen to be present in the use of photographic research from early examples through to the present. In their study of Balinese culture, Bateson \& Mead (1942) organised and integrated photographic images and descriptions in an attempt to accurately convey key aspects of Balinese life. The dignity of the people being researched is an important element, but it is not clear the extent to which these scholars had this in mind. More recently the protection of dignity has been paid particular attention to, for example, general medical/social research (Alderson \& Minto, 2002; Berle, 2008; Clark, et. al, 2010; Creighton, Alderson, Brown, \& Minto, 2002; Jones, 1994; Supe, 2003), and research focussing on people with intellectual disabilities (Boxall \& Ralph, 2009) and children (Close, 2007).

The application of visual methods in social research has been accompanied by an emergence of ethical issues of which dignity is an important aspect, particularly in the areas of social relations, poverty, and empowerment. In the area of social relations, Fink (2011) for example, uses photographs to gather data about community life, including the activities of children in playgrounds. This raises significant questions not only about consent but also about how a research participant's dignity can be protected. Once the image is captured and published, impressions (negative or positive) and interpretations of the situation and the individuals portrayed are largely beyond the control of participants and the researcher.

The idea that empowerment and identity are elements of dignity can be drawn from PhotoVoice and reflexive photography. In the PhotoVoice technique, employed first by 
Wang \& Burris (1994), participants are given a camera to collect photographic data about their social worlds. Participants control the data collection process as they determine the 'photo' and the 'voice' aspects; they have control of the camera and independently of the researcher, choose subjects to photograph that are relevant to them. PhotoVoice is based on three principles that help capture the idea of dignity in that: firstly, every human being is capable (when given the right tools) to perceive his or her surroundings or reality and find contradictions within it, secondly, power increases to those with voice, and thirdly, it empowers research participants in the research process and through this its impacts on policy and practice (Wang \& Burris, 1994). Wang \& Redwood-Jones (2001, p. 1) encapsulate this by arguing that PhotoVoice is a 'powerful photographic technique that enables people to assess the strengths and concerns of their community and communicate their views to policy makers'.

An alternative to PhotoVoice is reflexive photography. This technique brings the importance of a research participant's identity into focus. In reflexive photography participants capture their own identities (Boxall \& Ralph, 2009; Hurworth, 2004; Noland, 2006). In adopting such methods sensitivity to the dignity of participants is implied as those being researched choose how they want to be portrayed. However, this assumes that they are aware of the subtleties of how images are interpreted and used.

When considering dignity, research photographers are also faced with questions about how they communicate with those they are photographing, their motives, and how they ensure informed consent (Barker \& Smith, 2012; Rolph, et al., 2009). Taking photographs without consent is a form of 'outsider arrogance' that distorts the research being undertaken because 
there is an uneven power relationship between the researcher taking the photograph and those who are being photographed (Spencer, 2011).

In the case of researching poverty in contexts such as India, how consent is gained is a critical consideration in ensuring that the research is empowering to those being researched. Gaining consent from participants before capturing an image is then a vital ethical requirement and the researcher has responsibility to provide information about the research to participants (Alderson, et al., 2002; Boxall \& Ralph, 2009; Clark, et al., 2010; Wang \& Redwood-Jones, 2001; Young \& Barrett, 2000). Implementing this in the field can present challenges. Gaining consent is not as simple as having participants sign consent forms because in some social contexts (e.g., India), such an approach is not necessarily appropriate. In some communities there may be low literacy rates and cultural norms about resisting signing official-looking forms. Instead, in certain situations, a negotiation of verbal consent (including the intended purposes of the photograph) is necessary and sufficient providing the particular social and cultural context is fully understood so that consent is situated within local customs (Clark, et al., 2010). Through discussion with participants, they might also agree to be photographed without them being aware to obtain more 'natural images' (Wiles, Prosser, Bagnoli, Clark, Davies, Holland, \& Renold, 2008). There are circumstances though in which dignity cannot be ensured in this way. These include situations where participants might not fully understand what they are consenting to or it may not be possible to get consent from everybody especially in public places (e.g., incidental images of people in a crowd scene or people in the background of a photograph) (Wiles, et al., 2008). In the former case it is important to engage in dialogue with the person to be photographed and perhaps offer them a copy of the photograph to indicate appreciation of their participation (Banks, 2001). In the latter, care and attention should be paid to ensuring that the image is an honest 
and authentic portrayal of the social situation. Adopting a research ethic based on 'care, compassion and a desire to act in ways that benefit the individual or group who are the focus of the research' can help ensure the dignity remains a central concern (Clark, et al., 2010, p. 82). As Riessman (2005, p. 475) points out, conducting photographic research ethically and in a way that protects the dignity of participants 'involves on-going negotiations - a perspective...that reaches beyond the narrow, one-shot agreement spelled out in the typical informed consent document'.

The protection of anonymity and confidentiality is another ethical consideration associated with dignity. The problem with photographic research is that this is often not possible or even desirable (Wiles, et al., 2010). To preserve anonymity and confidentiality of a person in a photograph could mean blurring the image of their face resulting in the loss of an important dimension of the photograph (i.e., the person). This can be seen as a form of objectification in that a participant's identity is being somehow distorted or even erased. In trying to protect anonymity and confidentiality, the research photographer is at the same time faced with the possibility of compromising a participant's dignity. To resolve this apparent contradiction, attention should be paid to, 'what will happen to the image after it has been produced, rather than on the involvement in the research process as a whole', requiring the researcher to ensure a participant's dignity by focussing on the distribution of the photographs and limiting the scope of exposure in addition to securing informed consent (Close, 2007, p. $30)$.

The ideas about dignity discussed so far are founded on the rights of the individual. This perspective is one that has its moral foundation in Western cultures where individualist ethics are of prime importance. It is not surprising then that such ethics are widely applied by 
Western-based social researchers. This approach to research ethics though is not necessarily entirely appropriate for research in societies where collectives take precedence over the individual (Mattson \& Clark, 2011; Howard \& Donnely, 1986; Park, 1987). In such societies dignity arises from duties and obligations to others and is often constructed around honour (or 'face'), in which public acts can diminish or increase the standing of a person relative to others (Mattson \& Clark, 2011). It therefore behoves the researcher taking photographs to be sensitive to the context dependence of dignity.

\section{Dignity-in-Context and Photographic Data Collection}

For research photography the question arises about how an investigator is able to determine what images to capture in order to convey accurate and authentic accounts of complex social relationships encountered in widely diverse field situations. One way is through the application of 'ethics-in-context' in which it is accepted that ethics cannot be exported from one cultural context to another (Riessman, 2005). Applying this idea makes it possible to construct the concept of dignity-in-context. For example, dignity in one culture could be considered an indignity in another and therefore the researcher must be sensitive to the cultural norms of the communities they are researching (Lickiss, 2007). That is not to say though that certain cultural practices in which one group of people are treated with less dignity than another be adopted by a researcher simply because it a cultural norm. In a field context, applying dignity-in-context means being sensitive to the relativistic nature of social and cultural norms and entering into dialogue with research participants underpinned by a set of clear research ethical principles that protect their dignity.

These principles of dignity-in-context have two dimensions. The first, dignity-in-outcome, refers to the need for those being researched to benefit from the research, to present an 
authentic view of the situation, and to ensure the research does not demean or reduce the person it involves. This assists in deciding who/what to photograph. For example, when researching communities afflicted by poverty making sure researchers do not demean or reduce the people they are researching is important (i.e., do no harm). It is though also important to achieve something positive, so one of the aims of data collection and analysis should also be to develop new theoretical and practical insights that support and encourage better practice by policy-makers, governments, NGOs, and international organisations that will improve the lives of the communities being researched. The second is dignity-in-process that helps deciding how/when to photograph. This forces the researcher to consider how to involve research participants in the way images are captured, for example, choosing the right angle for an image, the right time to capture an image, and the impression it will give if and when it is published.

\section{Photography in Social Research}

A consideration of photographic research ethics and dignity should include an explanation of how they connect to the nature of the method itself. The methodological choices of the researcher have a significant effect on what is photographed, how photographs are taken, the way they are analysed, and the means of presentation; all of which have an impact on dignity (Allmark, 2010).

One perspective is that photographs are objective, accurate, and value-free representations of the world. Dignity is not at issue here because participants have given informed consent and the image captured is value-neutral and is simply a source of objective data. Photographs are in effect a mechanical means of recording images of the world that excludes the involvement of the person capturing an image apart from their role in operating 
the camera (Walden, 2005). It can be argued that this is a false assumption because photographs are constructed images that represent particular perspectives (Clark, et al., 2010) and the research photographer is an active part of the situation they are trying to capture (Arnheim, 1974; Clark, et al., 2010). Photographs may have an objective element but its capture is a product of the subjective perceptions of the researcher and their motivations that ultimately results in a representation of a situation from a particular perspective (Arnheim, 1974; Clark, et al., 2010). A photograph can be seen then as an image-idea - a representation of the real - in that an image of a situation will always be an image and not the situation itself and as such data collected are a product of the methods and techniques employed by a researcher (Kember, 1996). This problem of the representative, subjective nature of research photography means that any image captured is open to various interpretations that are not necessarily predictable. Adopting a dignity perspective requires subjecting the process of capturing, interpreting, and presenting research photographs to critical attention. In the particular case of researching poverty this is important because such people are vulnerable to risks such as exploitation, coercion, and stigmatisation by the unintentional release of sensitive data, and marginalisation from the research process (Wiles, et al., 2010). Taking the position that photographic research is a subjective process that affects and is affected by the researcher and participants sensitises us to the ethical responsibilities associated with ensuring dignity.

\section{Cases - Chennai, India}

This paper draws from a research project concerned with examining poverty reduction and capacity building in the city of Chennai located in Tamil Nadu, India. The research seeks to explore, identify, and understand relationships between the way in which poverty is understood and how this impacts on efforts by NGOs to break generational cycles that prevent 
people improving their capabilities and opportunities. One of the major data collection methods employed in this research is photography. In this research, photographs are used as a means of collecting data about context, situation and surrounding circumstances and capturing detail about particular moments in people's lives. Such data reveals detail about social processes that cannot be collected by other means. This significantly adds to the authenticity, integrity and rigour of the research. In particular the photographic method allows the recording and analysis of unstructured situational social contexts, providing opportunities for new conceptual insights to emerge (Basil, 2011). This research also employs the immediate use of images in that the LCD display on a camera can be utilised to show the participant the image of them that has just been captured by the researcher. This contemporary form of 'photo elicitation' encourages response and dialogue between researcher and participants (Frith \& Harcourt, 2007).

\section{Case 1: The Road and its People}

The first case is a situation in which an opportunity arose to capture an image of a man dressed in rags lying on a pedestrian refuge used by people crossing the street. The photograph had the potential to provide valuable, contextual data about the disparities of wealth in Tamil Nadu. The man appeared to be poor and homeless but was surrounded by a tumult of auto rickshaws, cars, and people passing by. The photograph was not taken as it had the potential to compromise the person's dignity. An assessment against dignity-inoutcome raised questions about whether the image would: (a) help the person it concerns through increasing awareness of a problem, (b) raise awareness about a social issue in Tamil Nadu, (c) provide authentic data about the situation, and (d) demean the person being photographed. After assessing the situation it was concluded that even if consent could be obtained, the image would not have helped create awareness of the problem, but simply sensationalise it. Furthermore, it would not have adequately provided a visual description of 
homelessness in Tamil Nadu. It was an isolated incident and as such would not have provided authentic data and demeaned the person in the image as the photograph would have perhaps elicited feelings of pity rather than valuable data.

This case illustrates the importance of spending time in a social context in order to achieve an understanding of the dimensions of dignity-in-context in that location. Increased exposure to the social and cultural environment without collecting photographic data allows for more discrete and non-invasive initial observation, and allows the researcher to gain understandings without the pressure of needing to collect photographic data. The dignity of research participants can then be ensured without compromising research rigour through interaction and communication, building rapport that can then be developed further through the use of a camera.

\section{Case 2: Chariots of Youth}

The second case is that of an early afternoon on the streets of Chennai, where an elderly man was riding a bicycle rickshaw, transporting eleven pre-school children back to their homes through the traffic and pollution (Figure 1). Applying the principles associated with dignityin-process, discussion with the man led to him agreeing that his photograph be taken, which was then shown to him and, with his consent, to the eager and curious children he was transporting home. The ensuing discussion about the photograph with the man resulted in additional data being collected about his visible happiness in taking the children to school and back home, and coping with the difficult working conditions in Tamil Nadu.

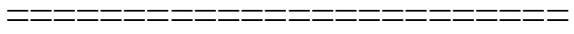

INSERT FIGURE 1 HERE 
Considering dignity-in-outcome raises the important consideration that research photography should not prettify people and their situation captured in an image as it could compromise their dignity. The situation captured in the photograph was not only data rich but also had an aesthetic quality in that the researcher and the participant were satisfied that it was a 'good' photograph - a highly subjective but important aspect in protecting or enhancing the self-esteem of the participant. This demonstrates the task of the research photographer in taking into consideration the aesthetic quality of an image alongside the need to collect data about the phenomena they are researching. The image captured in Case 2 contributed to achieving greater understanding of an issue in Tamil Nadu, is authentic in its depiction of the situation (it is common for elderly people in Tamil Nadu to engage in demanding physical work), and did not demean the participant, as they were the main focus of the image.

\section{Case 3: Family Gathering}

The application of dignity-in-process in the production of ethically sound and dignifying research photographs is illustrated in this case. The images were collected as a result of many visits to housing projects and slum areas in Chennai. Regular visits to the slum areas and being approached by children, young people, and adults for photographs and engaging in dialogue with people over time gave both them and the researcher an understanding of where the researcher stands in relation to the people being researched and vice versa. Photographic data was collected about the social world encountered in the slums including families taking their meal outside their house sitting on plastic chairs or a wall, elders gathering and chatting at the local temple, people enjoying chatter on the street, children running and playing with toys and tyres, and families gathering at weekends to socialise (Figure 2). Ensuring the dignity of participants was preserved demanded that the data collected about them be authentic. One particular aspect of dignity-in-process that emerged was the angle at which a photograph is taken. This is because verbal and non-verbal cues have a role in determining 
and reinforcing power structures (Hall, Coats, \& Smith Lebeau, 2005) not just in real-life but also in how people are portrayed in images (Tiemens, 1970), thus the angle of a photograph (from above, from below, or horizontally) affects how people evaluate the social status of the person being photographed. If a photograph is taken from below (looking up) the person in the image appears powerful whereas if an image is taken from above (looking down) the person appears powerless (Giessner, Ryan, Schubert, \& van Quaquebeke, 2011; Kraft, 1987; Mignault \& Chauduri, 2003). The use of visual cues in photographic research practice is therefore an important consideration for preserving or enhancing the dignity of those being photographed.

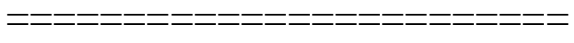

INSERT FIGURE 2 HERE

We decided that in this research it was important to not depict people in photographs taken 'from above' as it would tend to present them as powerless and perhaps a photograph taken 'from below' could be seen as being patronising (trying to create a false impression of power). In this study a horizontal angle was chosen as it conveys equality of status between the person(s) in the photograph and the person(s) viewing it (Fahmy, 2001). In Case 3 the use of a horizontal angle seemed to protect the dignity of those photographed, while not losing its intended research value.

\section{Case 4: Trades People}

Case four presents another dimension to dignity-in-process in that this photograph arose from visits to the slums in which data were gathered about trading and occupational practices in which people engage in front of, or in their homes. Of a number of images captured while collecting this data, one image was of a man sewing material in his home with an old pedal 
sewing machine on a simple wooden table while his spouse and two children were sitting outside in front of the house. Another image was of a woman sitting in front of her home putting together flowers from a basket on a string for the temples in company of her spouse (Figure 3).

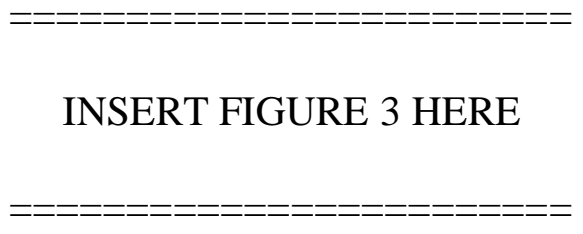

In this case it was important to consider what impressions were being conveyed about the participants and their social environment as well the value of an image to the research project before capturing an image. Experiencing the poorer areas of Chennai it became clear that care must be taken to collect data that accurately and authentically portrays their situation and dignifies whatever they are doing.

This case illuminates a common theme running through this analysis in that authenticity can be achieved by developing contextual understanding and sensitivity to those being researched. It is best described using the German term Verstaendnis. Verstaendnis encapsulates the notion of gaining understanding and empathy. By spending time in the field before collecting photographic data the researcher develops Verstaendnis ensuring that ambiguities and/or irregularities in those images are minimised. Adopting this approach demonstrates interest in the lives of people being researched and respect for their dignity. In Case 4 for example, it was found that collecting photographic data in this way provided valuable detail about work environments and practices, the context dependence of situations, and protected the dignity of participants. 
Drawing the four cases together we argue that photographing people in their social environment is taking something from them they cannot defend. This being a valid argument, spending time with people being researched and using the camera as a communication tool as well as a data collection tool, allows the barriers between the researcher and participants to be reduced helping to preserve and enhance dignity. The cases discussed above illuminate the process of capturing research photographs that take into account dignity-in-context. Drawing on field experience it seems that people being photographed for research benefit greatly by being shown the photograph taken on the LCD screen at the back of the camera. The person photographed can then see exactly how they are being portrayed in that particular moment, allowing them to raise concerns about a particular image of them or their situation (which might end in the participant asking that the image be deleted). To do this, it was necessary to give as much time as participants wanted to view relevant photographs. This ensures that participants are fully involved in the data collection process. While this might not apply to spontaneous snapshots of fleeting moments, time previously spent on understanding the social and cultural contexts of the scenes being photographed will help in the exercise of discretion when taking ethically sound research images. By adopting these approaches, the authenticity of photographs is ensured while at the same time safeguarding the dignity of participants.

\section{Conclusion}

The current literature on photography research ethics strongly emphasises the importance of informed consent, absolute clarity, accuracy, and controlled distribution of data. This paper adds to current understanding and ethical practice in research photography by expanding on the concept of dignity defined as being inherent to every individual, a Wesensmerkmal.

We began with Sontag's (1977) ideas about thinking and feeling in photography to 
establish that researchers need to consider the collection of this type of field data as a sensitive ethical issue within which dignity is a key element. Building on the idea of ethicsin-context (Riessman, 2005), this paper contributes through developing the concepts of dignity-in-context, dignity-in-process, and dignity-in-outcome. These provide a basis of practice guidelines for effective research photography ethics that have previously not received wide attention in the literature.

Through the employment of illustrative case studies, good practice in collecting photographic data is discussed. As an overall guide, researchers can apply the idea of dignityin-context as a way of sensitising themselves to the social and cultural norms of the community they intend to study and in doing to develop appropriate research ethics protocols and practice. Of the two dimensions of dignity-in-context, dignity-in outcome is illustrated in Cases 1 and 2. These cases pertains to the whether and what issues of photographic data collection in that attention is drawn to ensuring the research being conducted brings benefits to participants as well as protecting or enhancing dignity. Cases 3 and 4 illustrate dignity-inprocess. Taking account of dignity-in-process helps researchers address the why and how questions of photographic data collection in that firstly, it obliges the researcher to ensure that participants understand the motives and aims of the research being conducted. Secondly, it assists researchers choose how scenes are photographed and in doing so involves research participants in the data collection process. As a result, richer and more authentic images can be captured.

This exploration of research photography suggests that images captured not only contain data about participants and their social worlds but also reveal much about the research processes and ethics employed by the researcher. Taking the case studies together it seems 
that protecting the dignity of research participants necessitates dialogue and building relations with those being researched before data collection begins to develop Verstaendnis.

Undertaking more research exploring issues associated with research photography has the potential to further develop the notion of dignity and refine approaches to in-the-field practice. In particular, there is a need for more debate including closer examination of the wider implications of research photography, in particular the employment of digital technologies (e.g., web distribution, questions of privacy, and photo manipulation). Such research will serve to further enhance the application of the camera as a valuable data collection tool. 


\section{References}

Allmark, P. (2011). Towards a photographie féminine: Photography of the city. Visual Research Methods in the Social Sciences: Awakening Visions (pp. 171-183). Oxford: Taylor and Francis.

Andrade, A.D. (2009). Interpretive research aiming at theory building: Adopting and adapting the case study design. The Qualitative Report, 14(1), 42-60.

Arnheim, R. (1974). Art and Visual Perception: A Psychology of the Creative Eye. The New Version. Expanded and Revised Edition. Berkeley: University of California Press.

Banks, M. (2001). Visual Methods in Social Research. London: Sage Publications.

Barker, J and Smith, F. (2012). What's in focus? A critical discussion of photography, children and young people. International Journal of Social Research Methodology, 15(2), 91-103

Basil, M. (2011). Use of photography and video in observational research. Qualitative Market Research, 14(3), 246-257.

Bateson, G., \& Mead, M. (1942). Balinese Character: A Photographic Analysis. New York: New York Academy of Sciences.

Berle, I. (2008). Clinical photography and patient rights: The need for orthopraxy. Journal of Medical Ethics, 34(2), 89-92.

Boxall, K., \& Ralph, S. (2009). Research ethics and the use of visual images in research with people with intellectual disability. Journal of Intellectual \& Developmental Disability, $34(1), 45-54$.

Clark, A., Prosser, J., \& Wiles, R. (2009). Ethical issues in image-based research. Arts \& Health, 2(1), 81-93.

Close, H. (2007). The use of photography as a qualitative research tool. Nurse Researcher, 15(1), 27-36. 
Crang, M. (1997). Picturing practices: Research through the tourist gaze. Progress in Human Geography, 21(3), 359-373.

Creighton, S., Alderson, J., Brown, S., \& Minto, C.L. (2002). Medical photography: Ethics, consent and the intersex patient. BJU International, 89(1), 67-71.

Fahmy, S. (2004). Picturing Afghan women: A content analysis of AP wire photographs during the Taliban regime and after the fall of the Taliban regime. Gazette, 66(2), 91-112.

Fink, J. (2012). Walking the neighbourhood, seeing the small details of community life: Reflections from a photographic walking tour. Critical Social Policy, 32(1), 31-50.

Frith, H., \& Harcourt, D. (2007). Using photographs to capture women's experiences of chemotherapy: Reflecting on the method. Qualitative Health Research, 17(10), 13401350.

Giessner, S.R, Ryan, M.K., Schubert, T.W., and van Quaquebeke, N. (2011). The power of pictures: Vertical picture angles in power pictures, Media Psychology, 14(4), 442-464.

Harper, D. (2003). Framing photographic ethnography: A case study. Ethnography, 4(2), 241266.

Howard, R. E., \& Donnelly, J. (1986). Human dignity, human rights, and political regimes. The American Political Science Review, 80(3), 801-817.

Hurworth, R. (2004). Photo-interviewing. Qualitative Research Journal, 4(1), 73-79.

Joanou, J.P. (2009). The bad and the ugly: Ethical concerns in participatory photographic methods with children living and working on the streets of Lima, Peru. Visual Studies, 24(3), 214-223.

Jones, B. (1994). Ethics, morals and patient photography. The Journal of Audiovisual Media in Medicine, 17(2), 71-76.

Kember, S. (1996). The shadow of the object 1: Photography and realism. Textual Practice, 10(1), 145-163. 
Kraft, R.N. (1987). The influence of camera angle on comprehension and retention of pictorial events, Memory and Cognition, 15(4), 291-307.

Lickiss, N. (2007). On human dignity: Fragments of an exploration. In J. Malpass, \& N. Lickiss (Eds.), Perspectives on Human Dignity: A Conversation (pp. 27-41). London: Springer.

Mattson, D. J., \& Clark, S. G. (2011). Human dignity in concept and practice. Policy Sciences, 44(4), 303-319.

Mehnert, A., Schroeder, A.S., Puhlmann, K., Muellerleile, U., \& Koch, U. (2006). Wuerde in der Begleitung schwer kranker und sterbender Patienten. BundesgesundheitsblattGesundheitsforschung - Gesundheitsschitz, 49(11), 1087-1096.

Noland, C.M. (2006). Auto-photography as research practice: Identity and self-esteem research. Journal of Research Practice, 2(1), 1-19.

Parsons, S. (2009). Sontag's lament: Emotion, ethics, and photography. Photography and Culture 2(3), 289-302.

Pink, S. (2006). Doing Visual Ethnography: Images, Media and Representation in Research. London: Sage.

Prosser, J., \& Loxley, A. (2007). Enhancing the contribution of visual methods to inclusive education. Journal of Research in Special Education Needs, 7(1), 55-68.

Riessman, C. K. (2005). Exporting ethics: A narrative about narrative research in South India. Health, 9(4), 473-490.

Rolph, S., Johnson, J. \& Smith, R. (2009). Using photography to understand change and continuity in the history of residential care for older people. International Journal of Social Research Methodology, 12(5): 421-439.

Smith, M. \& Donnelly, J. (2004) Power, inequality, change and uncertainty: viewing the world through the development prism. In C. J. Pole (Ed.), Seeing is Believing? 
Approaches to Visual Research (Studies in Qualitative Methodology, Volume 7) (pp.

123 - 145). Emerald Group Publishing Limited: doi:10.1016/S1042-3192(04)07008-9.

Solomon-Godeau, A. (1994). Inside/Out. Basic Critical Theory for Photographers.

Burlington: Focal Press.

Sontag, S. (1977). On photography. New York: Anchor Books.

Spencer, S. (2011) Visual Research Methods in the Social Sciences: Awakening Visions. Oxford: Taylor and Francis.

Stanczak, G. (2004). Visual representation. American Behavioral Scientist, 47(12), 14711476.

Supe, A. (2003). Ethical considerations in medical photography. Issues in Medical Ethics, $11(3), 83-84$

Walden, S. (2005). Objectivity in photography. The British Journal of Aesthetics, 45(3), 258272.

Wang, C., \& Burris, M. (1994). Empowerment through photo novella: Portraits of participation. Health Education Quarterly, 21(2), 75-86.

Wang, C., \& Redwood-Jones, Y.A. (2001). Photovoice ethics: Perspectives from Flint Photovoice. Health Education \& Behavior, 28(5), 560-572.

Wellington, J. (2000). Education Research: Contemporary Issues and Practical Approaches. London: Continuum.

Wiles, R., Coffey, A., Robison, J. \& Heath, S. (2010). Anonymisation and Visual Images: Issues of Respect, 'Voice' and Protection, ESRC National Centre for Research Methods Working Paper Series 07/10.

Wiles, R., Prosser, J., Bagnoli, A., Clark, A., Davies, K., Holland, S. \& Renold, E. (2008). Visual Ethics: Ethical Issues in Visual Research, ESRC National Centre for Research Methods Review Paper NCRM/011. 
Young, L., \& Barrett, H. (2000). Adapting visual methods: action research with Kampala street children. Area, 33(2), 141-152. 


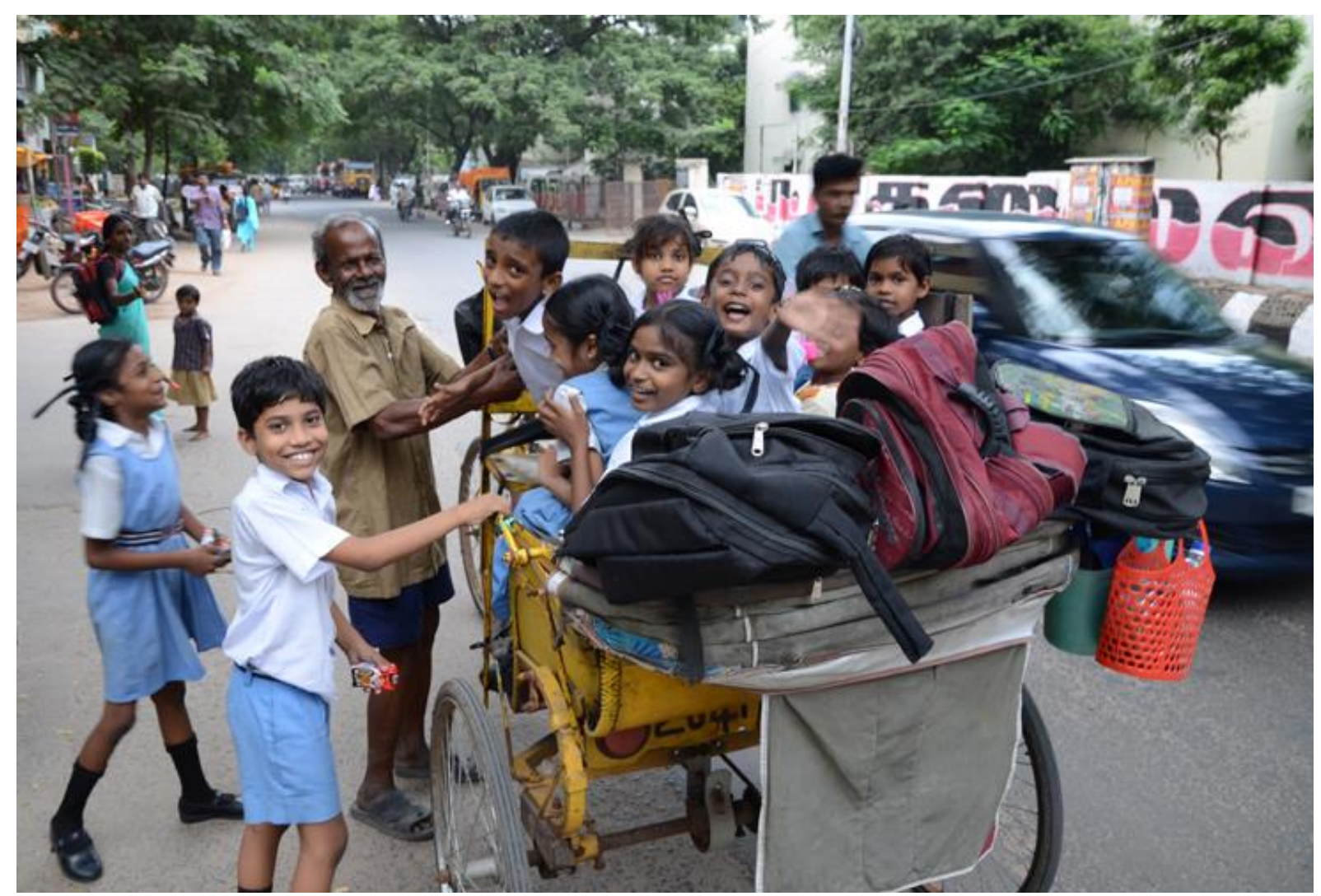

Figure 1. Chariots of Youth 


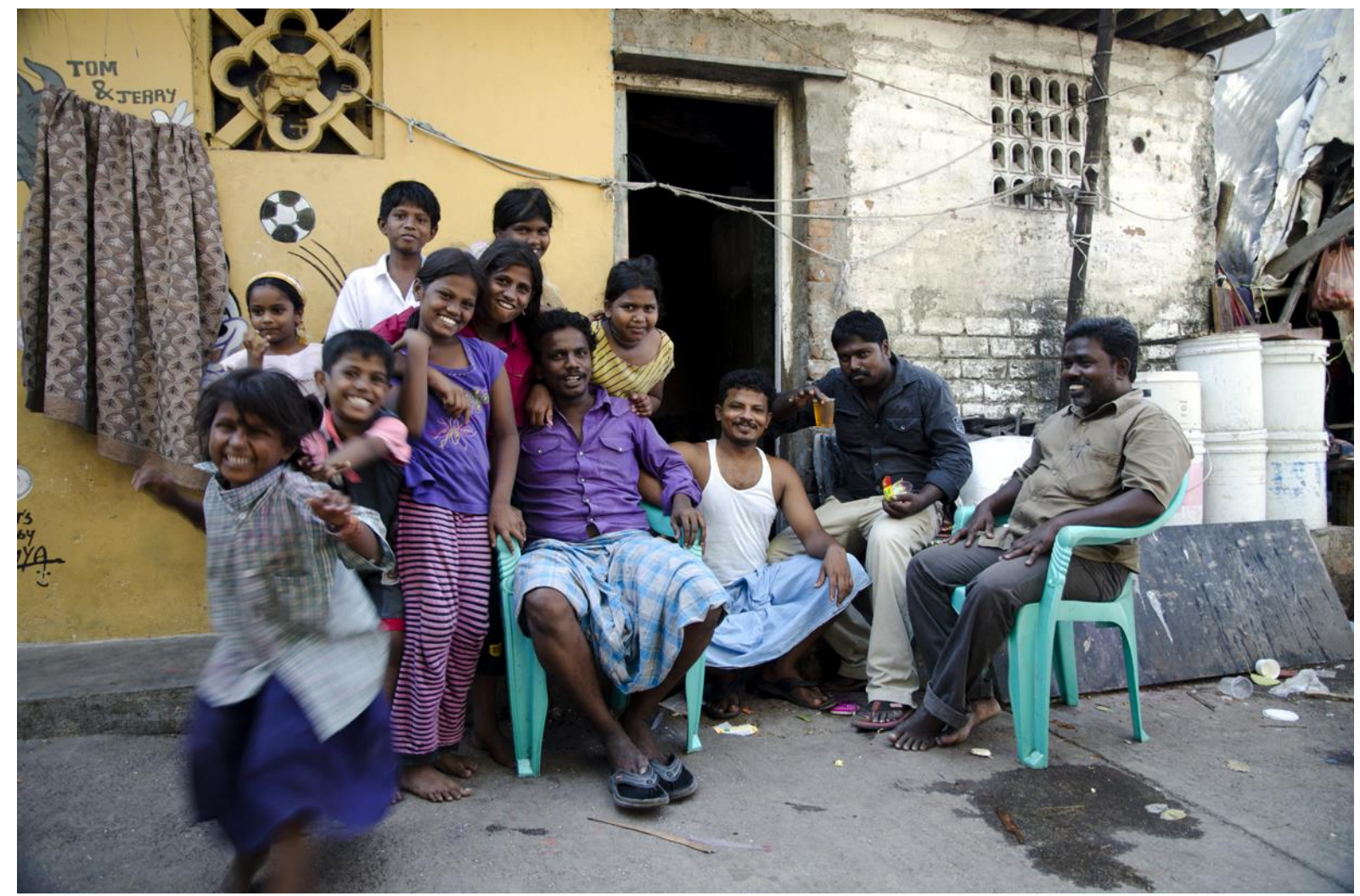

Figure 2. Family Gathering 


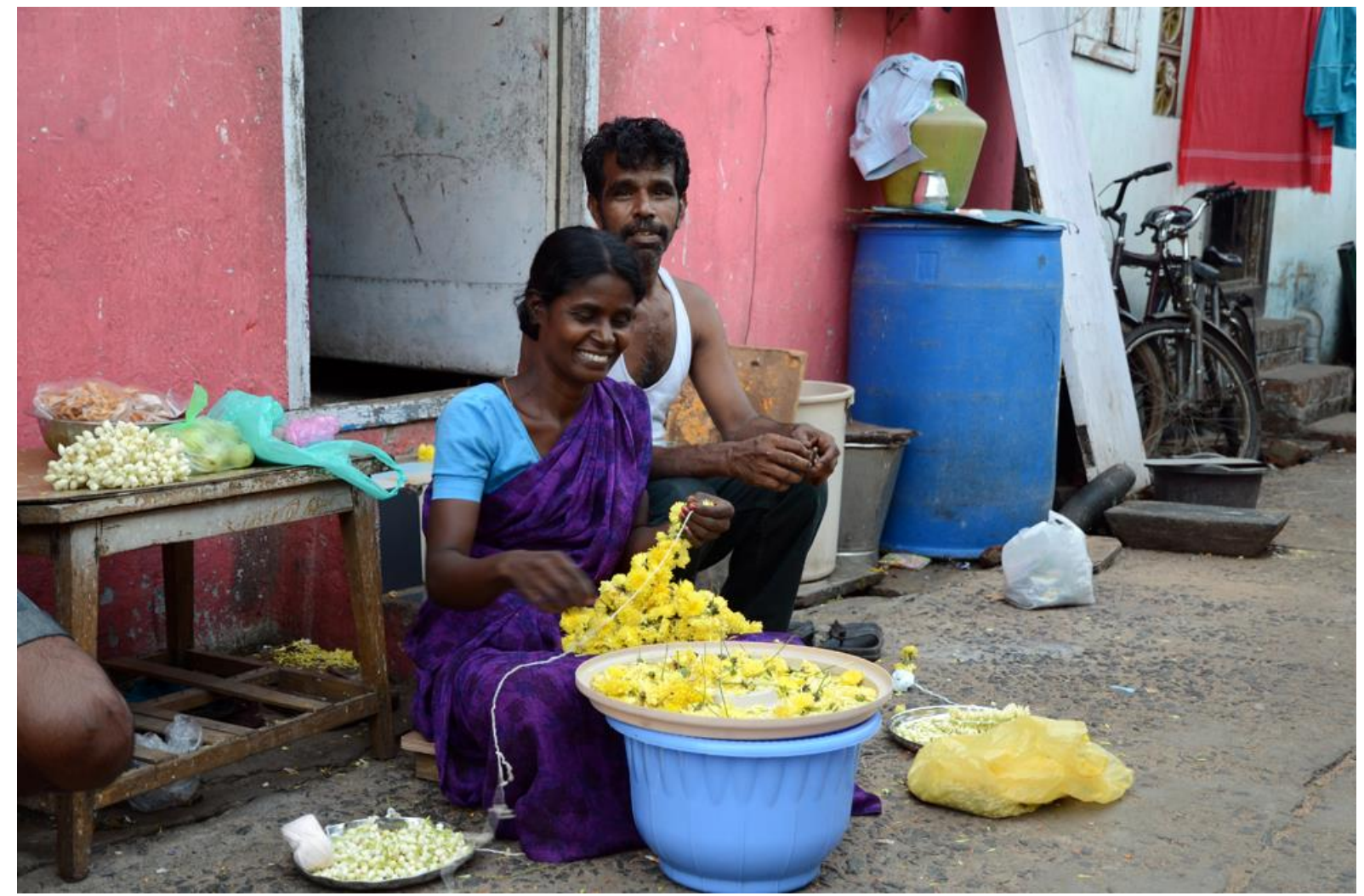

Figure 3. Trades People 